\title{
Blending out of the background: Play, props and staging in the material world
}

\author{
Chris Sinha \\ University of Portsmouth, Department of Psychology, King Henry Building, \\ King Henry I Street, Portsmouth PO1 2DY, UK
}

Received 19 September 2003; received in revised form 11 June 2004; accepted 21 September 2004

\begin{abstract}
The focus in blending theory on the dynamics of meaning construction makes it a productive tool for analysing psychological processes in a developmental perspective. However, blending theory has largely preserved the traditionally mentalist and individualist assumptions of classical cognitive science. This article argues for an extension of the range of both theory and data, to encompass the socially collaborative, culturally and materially grounded nature of the human mind. An approach to young children's symbolic play in terms of conceptual blending is presented, together with an analysis of an episode of sociodramatic play which highlights the role of cultural material objects as crucial meaning-bearing elements in the blend. From a developmental perspective, conceptual blending can be viewed as a microgenetic process, in which not only cognitive strategies, but social roles, relationships and identities are negotiated by participants in social and communicative interactions.
\end{abstract}

(C) 2005 Elsevier B.V. All rights reserved.

Keywords: Blending; Cognitive development; Cultural cognition; Integration; Symbolic play

\section{Getting cognition out from under the skin}

The theory of conceptual integration (blending) (Fauconnier and Turner, 2002) is one of the most innovative contenders in the crowded market of answers to the ever-engaging question: "What makes us humans so different and so human?" The focus of blending theory on the emergent, transient and fleeting aspects of language and thinking; its

E-mail address: Chris.Sinha@port.ac.uk.

0378-2166/\$ - see front matter (C) 2005 Elsevier B.V. All rights reserved. doi:10.1016/j.pragma.2004.09.011 
attention to the creative operations underlying apparently prosaic acts of communication and understanding; and above all its orientation to novelty: all testify to the distance which has been traveled from the algorithmic certainties of classical 'rules and symbols' cognitivism. These features of blending theory also suggest that it should offer a significant new theoretical tool to psychologists who are interested in developmental processes. Blending theory promises, especially, to shed light on microgenetic processes: those developmental advances occurring in the time-course of an encounter between a reasoner/ communicator, and a novel and challenging cognitive task. My first purpose here is to expand this argument, and to exemplify it by an analysis of just such an encounter.

The episode I analyze below is one of social, symbolic play by young children, involving linguistic interactions between individuals, and between them and their shared material and symbolic environment. The kind of cognition which it typifies is richly social, focused on objects and people, and apparently far removed from the "mental" problemsolving tasks often given as illustrations of blending theory.

When faced with such episodes of what has come to be known as situated cognition, blending theory can appear surprisingly traditional in its assumptions. Cognition tends to be viewed through the prism of the individual subject, and his or her internal mental processes. Despite the dependence of many analyses on shared experience and knowledge, the theory preserves to an appreciable extent the individualist and mentalist emphasis of classical cognitivism.

My first purpose here is to argue, in company with the contributions of Hougaard (this issue) and Hutchins (this issue), for a recasting of theory and method to more explicitly encompass the socially collaborative, culturally and materially grounded nature of the human mind. The argument is similar to that advanced in Sinha and Jensen de López (2000), with respect to the wider theoretical models of cognitive linguistics. There, we argued that the key notion of "embodiment" needed to be extended beyond its focus on the humanly corporeal, the "brain-in-the-body", to take account of the way that cognitive and cultural schemas find material realization-are embodied-in the artefacts of material culture; and the way in which such artefacts are themselves embedded in culturally appropriate, normative structures of action and interaction. In this perspective, mind is socially distributed between people, and mental processes are supported by objects which embody and represent them. Cognition extends beyond the individual; embodiment goes beyond the skin.

Fauconnier and Turner (2002), drawing upon the work of Hutchins (see Hutchins, this issue), explicitly acknowledge the importance of the material culture both in providing material anchors for cognitive processes, and in canalising human development. They write: "the culture is using material anchors at human scale ... to constrain the child toward development of its repertoire of integration networks" (Fauconnier and Turner, 2002: 216). It is this point that I am seeking here to elaborate and exemplify, but also to deepen, by emphasizing the way in which the materials "on hand", supplied by the culture, are bearers or signifiers of cultural meanings which are appropriated and negotiated by developing subjects within specific episodes of social interaction. Children do not confront alone, as isolated thinkers, either symbolic tasks, or the material anchors which facilitate their mastery of such tasks. Rather, they encounter the materials for development in contexts which are structured and "scaffolded" (Bruner, 1975) by interaction. 
This general perspective is by no means new, having been articulated early in the last century by the developmental psychologist Lev Semenovitch Vygotsky $(1978,1986)$, and since elaborated by (amongst many others) Bruner (1990), Cole et al. (1978) and Wertsch (1985). The Vygotskian tradition has enjoyed at best an uneasy, and often a downright antagonistic, relationship with mainstream linguistic and psychological theory. This has been as detrimental to the embattled Vygotskians, who have been tempted to retreat into exegetic ghettoization, as it has to the mainstream, which has patrolled and defended boundaries of what counts as "real science" that owe more to disciplinary policing, than to the multidimensional nature of the phenomena to be accounted for.

The trouble, however, runs deeper than sociology of science, important as this may be in the institutional arena of grants, publications and citations. Classical cognitivism, as has often been pointed out, is deeply indebted to, and predicated upon, a view of the relationship between "reality" and "representation" that can be traced back to Descartes, and which has been, ever since, the dominant motif of Western thought about thought. The Vygotskian quest for a coherent theory of mind based upon the primacy of social practice is deeply antagonistic to this tradition. ${ }^{1}$

A comprehensive and interdisciplinary approach to mind in context cannot be achieved by forcing a merger between fundamentally incompatible enterprises: there are structural conditions to be met, and mutual structural adjustments to be made, before the blend can productively be run. Why, if blending theory seems at first sight to be prone to the individualist bias of classical cognitivism, should we expect any better this time round than before? The answer, I suggest, is that blending theory, and the cognitive linguistics tradition from which it stems, invite just such a synthetic effort by virtue of the other theoretical commitments that they presuppose and develop. Foremost among these are a rejection of formalism as a goal, rather than as a proper methodological part, of the research process; and a discernible (if not always acknowledged) debt to the intellectual tradition of American pragmatism (Rohrer, 2001).

The affinities between Vygotsky and the pragmatists, especially George Herbert Mead, have been remarked by developmental psychologists ever since Vygotsky's work became widely available in English translation (e.g., Lock, 1978). The similar affinities between experientialism in cognitive linguistics, and pragmatism, give grounds for optimism that an encounter between blending theory and the Vygotskian, socio-cultural tradition may be beneficial and informative for both parties. As good pragmatists would insist, the best defence of this proposition is to see what additional light it might shed on particular episodes in which human beings think, in interaction with each other and with objects.

The real-life example I will discuss involves children in interaction with other children, without the intervention of adults. Developmental psychologists have long emphasized the guiding role of cognitive scaffolding provided by developmentally more advanced mentors (Wood et al., 1976), but symbolic play offers an arena in which analysis can focus instead on the mutual construction of such scaffolding by children themselves, and on the kind of

\footnotetext{
${ }^{1}$ Vygotsky's account of mind as material practice was, of course, deeply influenced by Marxian social theory. Although I emphasize below the similarities between Vygotskian and American pragmatist theories, one can also point to the affinity between Marx's account of social practice and the philosophy of the later Wittgenstein (Rubinstein, 1981).
} 
emergent meanings that blending theory is uniquely suited to address. Finally, I will end up by suggesting that developmental thinking can be just as useful to Blendistas, as blending thinking can be to developmental psychologists.

\section{Representations, artefacts and fictive worlds}

\subsection{Representations}

The cornerstone of classical cognitivism is the concept of mental representation. Mental representations are seen, definitionally, as standing in some kind of relationship to the nonrepresentational material world, in which the crucial property of the mental representation is simply that it represents. Representation is therefore a relationship between mind and reality, and in complementary fashion, this representational relationship is criterial for mind. Without mind, no representation, and without representation, no mind. The prototype of mental representation, from which, in some accounts, all other kinds of representations are derived, is a symbol or a rule governed combination of symbols.

The Cartesian trap into which this account is liable to fall is that of positing some kind of mental "substance" whose essence is simply the capacity to represent. Most cognitive scientists, being scientific materialists, reject such a conspicuously dualist hypothesis, opting instead for the view of mental representation as a property of a physical symbol system. The brain is conceived of as just such a physical symbol system, though only one instance of a larger class which includes other computational devices. I will not rehearse here the many objections which have been raised against this theory, including those deployed in Searle's famous "Chinese Room" thought experiment (Searle, 1980). The only point I want to emphasize is that the physicality (or materiality) of the supposed mental symbol system, whether biological or electronic, is neither here nor there when it comes to accounting for its symbolic, or more generally representational properties. This is uncontroversial, and indeed it was the appreciation of the import of this point that led many cognitive scientists to accept the "functionalist" interpretation of a computational theory of mind against which Searle's critique was directed.

The problem, however, is that stipulating that the symbol system constituting mental representation is physical only postpones the Cartesian problem, it does not solve it. It can only be the systemic and/or relational properties, not the physical properties, of the representational system which make it representational. ${ }^{2}$ To unpack this: If the intrinsic physical properties do not (in themselves) account for the representational properties, then the latter must be explained by recourse to some other properties of the representation which are either systemic (such as computational or formal properties), or relational (pertaining to the relationship between representation and reality, such as truth). It would be an exaggeration to say that anyone has decisively shown that some such explanation is, in principle, impossible; but it is no exaggeration to say that no-one, until now, has

\footnotetext{
${ }^{2}$ Once Searle had established (at least to his own satisfaction) that the proposed non-physical properties of physical symbol systems could not account for their representational properties, he concluded that neurobiological properties must be responsible.
} 
managed to produce a convincing explanation of this kind, and the seeming futility of the enterprise has led to an impasse in classical cognitivism (Fodor, 2001).

One response to the crisis of cognitivism has been to claim that the concept of representation is not only flawed but superfluous, and that all cognitive processes can be accounted for in terms of non-representational properties of complex physical systems: cognition only needs complexity, and both representation and symbolization can be dispensed with altogether. The obvious objection to this move is that it throws out the baby with the bathwater, and that, while not all intelligent systems require representation, adult human beings live in worlds which are as much symbolic as physical, and utilize representational devices, systems and reasoning to get around in it. If classical cognitivism ended up by erecting a solipsistic barrier between mind and reality, complex systems theorists end up by collapsing all higher cognition into a bio-mechanical physicalism. There must be some way out of here!

If there is a way out, it has to involve re-thinking, rather than rejecting, representation, including mental representation. The theory of representation for which I argued in Sinha (1988), and which I maintain offers a consistent, non-cognitivist account of cognition, rejects formalism, essentialism and physicalism. It is based upon a pragmatic-semiotic account of representation which is materialist but not physicalist. ${ }^{3}$ In other words, the world of imagination and symbolization is not discontinuous from the material world, but practically intertwined with, and ontologically embodied in this world. At the same time, representation is irreducible to physical properties, of brains or anything else. There is no "essence", physical, mental, or formal, from which the representational properties of representations can be derived. Some key axiomatic propositions of this account are:

1. Representation is not a relationship between "mind" and "reality", but a cognitive and semiotic relational category within and constitutive of human ecological reality.

2. Scientific explanations of cognition should be consistent with a scientific materialist world view, in which there is no place for a non-material reality. I assume that the category "material" includes such entities as forces and energy, but does not include "ideas". Ideas play a role in history, in science and in biography, but how we come to have ideas in general (as opposed to a particular set of ideas) cannot be explained by appeal to an immaterial, purely ideational sphere of reality.

3. Some properties of reality are non-physical, for example, word meanings, monetary values, and institutions such as legal and kinship systems.

4. Non-physical properties of reality (non-physical types, including representational types) are embodied in material tokens. There cannot be a meaning without a signifier, or a monetary value apart from a monetary token or commodity which is valued, or an institution of marriage without embodied human beings whose status and practices the institution regulates.

\footnotetext{
${ }^{3}$ Physicalism denies the existence of entities, properties and relations which are non-physical, and is a form of reductionism which claims that all properties of the world can be redescribed as physical properties, such a redcecsription being the goal of science. Materialism, in the sense that I intend it, asserts that there is a material substrate for everything (including for example meaning), but that some properties of the world (e.g., meaning) cannot be reduced to their physical properties.
} 
5. Any instance of material reality can be a representational sign, given appropriate, socioculturally normative conditions on practice. A large part of human ecological reality (encompassing all artefacts and all signs) is representational.

6. Although things can be representations, representations are not things, in the sense that there is no essential quality which makes a representation a representation. A representation is a representation in virtue of normative conditions on communicative and significative practice, not because of its intrinsic properties. This applies as much to a painting or a photograph as to a morpheme or a milestone.

7. Mental representations are uses of capacities of the mind, based in neural processes but referring to the world, including symbolic and fictive worlds. To put this point as simply as possible: although an imagined Ferrari is indeed a "mental counterpart" of a real Ferrari, acts of linguistic reference to real Ferraris (or imaginary Unicorns) do not derive from such mental counterparts, but from conditions on communicating about Ferraris and Unicorns in the varied universes of discourse in which these are represented (some of which are actual and some fictive).

\subsection{Artefacts}

The ecological world of any organism, as J.J. Gibson (1979) observed, is a world of affordances for action. By this, Gibson meant that the objective properties of any segment of reality are relevant to an organism, to the extent that the organism can engage with these properties in its behaviour. The affordances of things in the world (their graspability, edibility, or whatever) are thus relative to the organism, constituting its environment for effective action. The specifically human world is one many of whose affordances are themselves intentionally designed by human agents. ${ }^{4}$ The world we live in is largely constructed, not so much in the social constructivist sense of being created out of talk and texts, but rather in the social materialist sense of being created by human productive activity. Human ecology, in all cultures, is to a greater or lesser extent an artefactual ecology, and human practices are artefactually supported, sustained and reproduced. To learn to be a competent member of a culture, it is necessary to master the use of, and in some degree the techniques for producing, the artefacts of that culture. Artefacts are of diverse kinds, including tools, buildings, notational systems, images and texts. Vygotsky drew an analogy between signs and tools, regarding tools as implements directed to the transformation of the outer, material world, and signs as implements directed to the transformation of the inner, cognitive world (the subjective world, as well as the intersubjective, mentally shared world).

However, the analogy goes further than this. Tools, and artefacts more generally, can also be regarded as representations, and this is as much the case for the everyday artefacts of material culture as for obviously "semiotic" artefacts. Artefacts are not (except for textual artefacts) texts, but they can be "read" like texts. A tool, for example, embodies in

\footnotetext{
${ }^{4}$ Gibson failed to realize the implications of this. The affordances of objects for cognitively complex organisms such as humans are fluid and flexible. To paraphrase Wittgenstein, the limits of the affordances of my world are the limits of my imagination.
} 


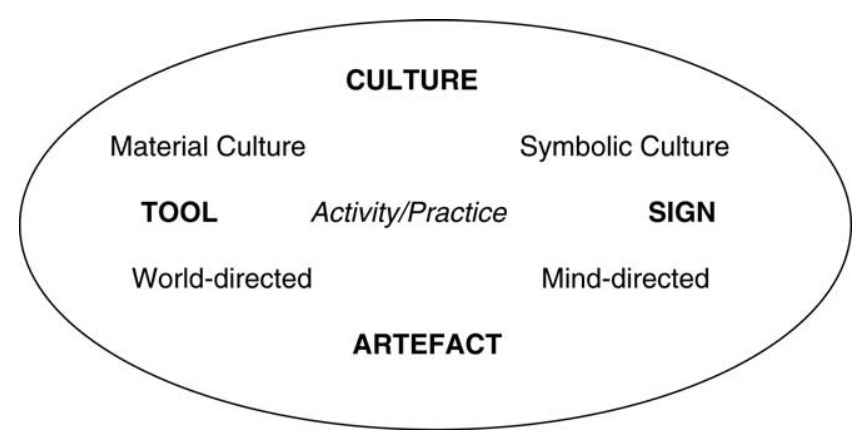

Fig. 1. Culture and artefacts.

its material structure the activity of using the tool, the interface between the human body and some sector of the natural or constructed material world. A piece of furniture, such as a chair, materially represents the structure of the human body, and simultaneously constrains the disposition of the body parts. Similarly, a cup represents a canonical case of containment, and in being a container it is a material representation of the conceptualization of containment by its producer and its user. Artefacts represent the practices that they support, constrain and potentiate, and the cognitive capacities which are implicated in these practices. The artefacts of a culture, then, are in a quite literal sense a material representation of the conceptual inventory of the culture, representing both material praxis - as a tool represents its functional use value-and representational or symbolic practices - as a diary represents the calendric system underlying its mnemomic and planning uses (see Fig. 1).

Artefacts are not simply externalizations of pre-existent, inner conceptualisations. Many cognitive practices are entirely dependent upon technologies; the cognition supervenes, to use the philosophical term of art, upon the artefact as much as it supervenes upon the brain. This is the point that is central to Hutchins's (this issue) argument. Realworld cognitive problem solving is distributed both between different individual problem solvers, and between the problem solvers and the artefacts that sustain the problem solving, and these are complementary aspects of the social distribution of cognition. This is easy to see when discussing symbolic technologies such as computational devices, but it applies to non-symbolic technologies too. The representation of human cognition cannot be sought in the human brain alone: the products of human cognition and human practice are all around us, in the artefactual world which is both inherited and renewed with each new generation.

Artefacts exist to be used. This use is constrained by the material characteristics of the artefact, which are intentionally built in by the human designer, and by conventions of use which mediate between these material characteristics and the functional ends to which the artefact is put. Hence, artefacts embody or represent the canonical or socially conventional modes of both practice and conceptualization (a cup is a container; containment is conventionally realized by the class of containers). Such conventions are not arbitrary but motivated, by practical purpose, and constrained, by form. In this respect, too, an analogy can be drawn between sign and artefact, specifically, between the functional-cognitive 
foundation of linguistic conceptualization, and the form of its expression. And just as the linguistic expression signifies the conceptualization motivating linguistic usage, the artefact signifies the practical conceptualization involved in material usage.

However, practical usage is not necessarily all that is embodied in an artefact, which may also represent aesthetic, cultural and symbolic values. Artefacts are frequently complex and multi-layered, and they do not "announce" all the values they represent independently of the "enunciation" of these values in the discourses and practices which frame their usage. For example, a Ferrari or a mobile phone is not "just" a car or technological communication device, but also an object of consumer desire, a signifier of social or monetary status and an index of social identity. Artefacts, like words, may be polysemous, and their multiple meanings are framed not just by the object "in itself", but also by the subjective position and perspective of the user, maker or mere observer of the artefact. The world of things is imbued with human subjectivity and human values and perspectives; it is simultaneously "actual" and "virtual".

\subsection{Fictive worlds and symbolic play}

The materiality of representation, and the virtuality of experienced reality, are two sides of the same coin and two ends of a continuum. One of the most important insights of cognitive linguistics is that most acts of linguistic reference are simultaneously acts of cognitive and linguistic construal (Langacker, 1987; Talmy, 1996). The notion of construal can be simply illustrated by example. Any referential situation which requires characterization in terms of the relationships obtaining between more than one entity may so be characterized in more than one way. I can say, for example, that the cup is on the saucer, or that the saucer is under the cup. In the first case, the cup is the Figure (or Trajector), and the saucer the Ground (or Landmark) in relation to which the location of the cup is specified. In the second case, these cognitive roles are reversed. Similarly, the lexicalisation "parent of" represents the same relationship as the lexicalisation "child of", but the two lexicalisations are perspectivized or profiled from different points of view. It is likely that the cognitive capacity for flexible construal is specific to the human species; at any rate it is uniquely developed and uniquely exploited in adult human cognition and in human natural language.

Construal in language often involves the superimposition of virtual properties onto the referential situation that is being conceptualized and construed, as has been emphasized in the case of spatial conceptualisations by Talmy (1996), who designates usages such as the following as instances of "fictive motion":

\section{The tunnel goes from Dover to Calais}

In this example, the tunnel is neither actually going anywhere, nor conceptualized by the speaker as going anywhere, nor represented by the utterance as going anywhere. The utterance represents the location and disposition of the tunnel as static, but it does so by employing "fictively" a dynamic conceptualization schema. The path of virtual motion implicitly evoked by the utterance is not that of the tunnel (moving tunnels would not be good tunnels!), but that of an experiencer traveling the length of the tunnel. This construal 
also involves a perspective in which the source of the path is Dover, or the English side of the Channel, and its goal is Calais, or the French side of the Channel. (1) would be an unusual usage for a speaker situated in Paris, who would be more likely to use:

\section{The tunnel goes from Calais to Dover}

Understanding fictive motion of this kind depends, then, upon a blend of a perspectivized path of virtual motion with the conceptualization of a tunnel as a landmark affording motion on a path (see the contributions by Hougaard and Hutchins, this issue). It therefore depends upon our background knowledge not only of embodied human movement, but also of the human intentionality embodied in the tunnel as a material object.

Virtuality is of the essence of blends, but so is reality. Even entirely fictional discourses depend upon our grasp of a Universe of Discourse which goes beyond the narrative to implicate an intricate network of social knowledge. Take for example:

\section{3. "Bring your service revolver, Watson", said Sherlock Holmes.}

To fully comprehend this utterance involves the knowledge that the NP "your service revolver" refers to an exemplar of a standard type of weapon issued to Army officers, retained by Dr. Watson after his discharge from military service, a retention which was legal and quite customary in the social world of 19th century England (though it no longer is). This historical world of facticity interpenetrates with the ficticity of the narratives in which the characters of Holmes and Watson exist. It is precisely the rich, but often implicit, evocation of the social world of late Victorian England which guarantees the enduring appeal of Conan Doyle's Sherlock Holmes stories. It should not, either, be forgotten that the "facticity" presupposed by the stories is also perspectival and idealized, reflecting the value system and social positioning of a leisured, masculine social group. In this sense, the Sherlock Holmes stories evoke and presuppose not only a "factual" social microworld (though facts abound), but also the cultural model shared by Conan Doyle with other members of his historical class, nationality and gender.

If fiction blends reality and virtuality, assertions of fact may invoke fictional worlds to sustain and construe joint reference. Take for example:

\section{Mickey Mouse was a pedophile ringleader.}

The fictive context of this (invented) utterance is one in which "Mickey Mouse" refers not to the fictional character immortalized by Disney, but to an employee whose job is to impersonate the character at Disneyland. The reference to the impersonator or actor by way of the name of the fictional character implies the co-ordination of two mental spaces, the literal and the fictional, in such a way that reference to an individual in the former (whose name may be unknown) is achieved by using the mutually-known name of the individual in the latter. To take a simpler example, one moviegoer might say to another "I thought the evil scientist was really good", apparently uttering a contradiction, but for the listener 
easily comprehensible as referring to the art of the actor playing the evil scientist. ${ }^{5}$ The blend in (4) is more complex, depending not only (i) upon our understanding of the fictional world of Mickey Mouse stories, but also (ii) upon our background knowledge of the kind of plans and ruses used by pedophiles to come into contact with children, and (iii) our background knowledge of the social institution exemplified by Disneyland: the theme park.

Theme parks are curious institutions: they are in fact institutional blends of fiction and fact. Although they seem to be characteristically modern, their semiotic properties are very ancient, being essentially theatrical. The world which we enter when we enter a theme park is fictive, inasmuch as the meanings of the buildings, events and characters that we encounter are grounded or anchored in fictional narratives (fairy stories, films or historical depictions). This world is also real, inasmuch as these fictions are embodied or materialized in the buildings and persons which stage the stories. A theme park is an elaborate staging with manifold theatrical props, which we are invited to participate in, as well as merely to observe. Theme parks are fictional interactive museums, in which the timeline is referenced to a virtual universe of discourse. ${ }^{6}$ It is the mapping between a fictional cartoon character and an acted character which permits the identification of the actor by the name of the character acted in (4) above. Hence, it is important to note that the Universe of Discourse which sustains the utterance's referential properties is not the narrative universe of Disney films, but the theatrical, blended universe of Disneyland.

Theme parks are spaces designed for audiences, and especially for child audiences. What do young children understand of the semiotics of theme parks, and of the imaginative blends that underpin them? It is well known that the boundaries between fiction and fact seem more permeable for children than for adults; and nowhere does this seem to be more apparent than in symbolic play. Both Piaget (1977) and Vygotsky (1986) maintained in their early writings that young children's thinking was "magical" and "prelogical", symptomatic of a concretism and syncretism of thought in which signifier and signified are undifferentiated. Drawing on the work of the anthropologist Lévy-Bruhl (1918), they considered that such concretism was characteristic of "primitive" thought in general, displayed by non-Western cultures and regressed to in schizophrenic psychoses. ${ }^{7}$

\footnotetext{
5 "The evil scientist was really good" seems to qualify as a blend. It could also be argued that it is a synechdoche, a species of metonymy, defined by the 1984 Longmans Dictionary as "a FIGURE OF SPEECH by which the part is used to mean the whole ..., the whole to mean a part . ., the species to mean the genus ..., the genus to mean the species, or the name of the material to mean the thing made (e.g., boards for stage)". Maybe it would be legitimate to extend this definition to include using the name of the role played to mean the entity playing the role (e.g., the lead for the actor playing the leading role).

6 Nowadays, museums seem to be becoming more like theme parks, in which "real" exhibits are contextualized by props and stagings as much as by texts, and in which visitors are invited to participate as well as to observe.

${ }^{7}$ [Autistic thought] is the thought of the child, of the neurotic, of the dreamer, of the artist, the mystic. It has also been studied by Lévy-Bruhl under the name of prelogical thought, of which the principal characteristic amongst primitive peoples is its fusion with magic (Piaget, 1977 [1920]: 56). It is therefore our belief that the day will come when child thought will be placed on the same level in relation to adult, normal and civilized thought, as "primitive mentality" as defined by Lévy-Bruhl, as autistic and symbolical thought as described by Freud (Piaget, 1977 [1924]: 117). The use of concrete images instead of abstract concepts is one of the most distinctive traits of primitive thought. Thus the child, primitive man, and the insane ... all manifest participation — a symptom of primitive [thinking in complexes] and of the function of words as family names (Vygotsky, 1986: 130).
} 
Such a manifestly Eurocentric interpretation of a generalized "primitive and childish mentality" did not, fortunately, survive in the later work of either Piaget or Vygotsky. Piaget, whose later theories were predicated on cognitive universalism, viewed early cognitive development as in large part the development of a generalized "semiotic function", or representational capacity. He viewed symbolic play as a prime instance of "representation", which he defined in terms similar to Hockett's (1960) linguistic notion of "displacement", that is, the evocation in thought or language of a real or imaginary situation or entity which is outside the spatio-temporal frame of the "here and now", and is therefore not directly perceivable.

Vygotsky regarded symbolic play primarily as a means whereby children internalize social relationships and conventions, and acquire the symbolic tools for negotiating shifting dialogic participant roles. As Oliveira (1998: 111) puts it, "Children's pretend play in naturalistic situations with an 'as if' atmosphere allows for the examination of internalized rules and images related to the partners' roles". Although the "social" perspective of Vygotsky has often been contrasted with the "individual" perspective of Piaget, contemporary socio-cultural constructivist approaches in developmental psychology have emphasized the complementarity of these two perspectives (Valsiner, 1998), while insisting on the constitutive role of cultural canalisation in the development of cognition and communication. It is in this spirit that I propose that the theory of conceptual blending can offer new insights into developmental processes in children's symbolic play. As we shall see, however, the theory is itself transformed by fully embedding it in the social material and social interactive world, rather than confining it to the individual, inner mental, world.

Symbolic play encompasses play with objects, as well as socio-dramatic play. Symbolic play with objects emerges at the transition from the second to third year of life, and sociodramatic play at about 4 years of age. Characteristic of all symbolic play is pretence: the child pretends that an object is other than what it really is, or that he or she is a different person than he or she really is. Symbolic or pretend play involves the projection of imaginary cognitive and symbolic value onto entities and relationships in the child's immediate environment. The entities may be objects, as for example when a child pretends that a stick is a gun, or animates a doll through making it speak, act or interact. They may be social roles, such as when children play school or play mothers and fathers, adopting roles and perspectives of imagined others. And they may be entire settings, such as when children construct a play house or play in a play corner, allocating roles, functions and identities to both human participants and the things to hand which serve as the props to the staging of the symbolic play.

Symbolic play is thus an instance of "virtual cognition", in which the imaginary and the real fuse or blend into an experiential arena in which the "mental" and the "physical" are, as it were, dissociated from their customary, conventional or canonical correlations, and reassembled in a new, blended space. The characteristics of the play space are primarily governed by the knowledge of the player(s) about the "play domain", and this knowledge over-rides the immediate and conventional affordances of the physical setting. In this respect, symbolic play represents a crucial step in the actualisation of the symbolic power of language as a vehicle for the construction of imaginary and counterfactual mental spaces. However, it is significant that this step is not achieved through a "retreat from" or 
"replacement of" the actual material world of the setting. Rather, the actual setting is backgrounded, and then re-incorporated into the symbolic play space. This process, in shared symbolic play, often involves social negotiation of the symbolic values to be accorded to the elements of the setting (including, but not only, the human participants). In the microgenetic process of symbolic play, a central role is therefore played by the material world, as a world saturated by socially shared meaning and value.

\section{The cowboy, his hat and the girls}

The transcribed play episode below is reproduced with permission from Smolka et al. (1997). It is translated (by these authors) from Portuguese into English, and is a segment from a transcribed observation of socio-dramatic play by three girls in a Brazilian primary school classroom. The play was not elicited by the researchers, but spontaneously produced. Although the act of transcribing and analysing this episode inevitably draws attention to the creativity and cognitive complexity of the children's play, the episode is not untypical of the way that young children weave the material resources at hand into the narrative flow and symbolic challenges of spontaneous, collaborative play.

\subsection{Background, stage and enactment}

There is a popular Brazilian theme park called Beto Carrero World. Beto Carrero is the proprietor, but also the eponymous cowboy hero protagonist, of Beto Carrero World. Beto Carrero "himself" sometimes appears in Beto Carrero World, mounted on his white horse and wearing his white cowboy hat and gear. This is in itself interesting. Beto Carrero the artist and proprietor is real, and Beto Carrero is his real name. However, Beto Carrero, the cowboy hero of Beto Carrero World, is not identical to Beto Carrero the artist and proprietor, although they share the same name. The cowboy Beto Carrero is a fictive character, a role enacted by the artist Beto Carrero. Is Beto Carrero a blend? Without getting overly metaphysical, it seems fair to say that the expression Beto Carrero World blends the different identities assumed by Beto Carrero, and signifies an institutional blend (a theme park) similar to Disneyland. Importantly, however, for the children who are the main clients of Beto Carrero World, Beto Carrero is primarily (perhaps exclusively) the cowboy character Beto Carrero, associated with his cowboy attributes, including the most important of these, his white cowboy hat. The hat can reasonably viewed as both an attribute of the character, and a signifier of his being a cowboy and a "good guy". As we shall see, this is important for the analysis of the play episode.

The play is staged in the house corner of a primary school classroom, where there are props including a cowboy hat. The participants in the socio-dramatic play episode are three 5-6-year-old girls: Alcione, Thaís, Camila.

At the beginning of the transcribed segment, Alcione is in the role of Thaís's daughter, Tháis is in the role of Alcione's mother, and Camila has no role yet assigned. Suddenly, the cowboy hat falls off a shelf and Alcione picks it up and puts it on. This is the beginning of the enacted episode. 


\subsection{Transcript (translated from Portuguese)}

1. Alc: (to Tha.) You were, you were ... Do you want to play with this hat? (puts hat on Thaís' head, who takes it off again and puts it aside)

2. Alc: Then give it to me, give it to me, Thaís! (picks up the hat)

3. Tha: (to Alc.) Honey, mom doesn't like hats (Alc. puts the hat on again and looks at Tha.)

4. Tha: You look pretty!

(Alc. laughs. Camila takes the hat from Alc. Tha. is writing)

5. Tha: (to herself and/or the group) Veronica

(writing down the name she has given herself)

6. Tha: (to Alc.) What's your name?

7. Alc: My name is ... mine is Bete, Bete Carrera

8. Cam: (to Tha.) Mine is Bete Carrera too.

9. Tha: (to Cam.) Ahn. . . it can't be. Then I'm called ... Bete.

10. Alc: (to others) I'm called ... I'm called ...

11. Tha: (to others) I'm called Bete Carrera!

\subsection{Analytic gloss}

In turns 1-4, Alcione and Thaís are engaged in a dialogue whose setting is "house", and whose universe of discourse is the fictive mother-daughter relationship between them. They are enacting familiar roles, exchanging comments about the hat and their appearance when wearing it. The hat, in this universe of discourse, is a feminine attribute, evaluated according to whether it is comely for the wearer. The hat is exchanged between them. At the end of turn 4, the hat is taken by Camila, who has not yet engaged, and has no role assigned, in this universe of discourse. At this point, Thaís decides it is time to assign names to the characters, starting with herself, in turn 5, in which she claims (in the role of "mother") the name "Veronica". In turn 6, she asks Alcione to assign a name to her role as "daughter".

Turn 7 constitutes a break, involving the introduction of a new dimension in the universe of discourse. Alcione claims the name "Bete Carrera", suggested by the hat. Notice, now, that "Bete Carrera" is a grammatically regular feminization of "Beto Carrero". Alcione displays here her knowledge of grammatical gender in her native 
language, as well as employing this knowledge to signify her gendered identity. The form "Bete Carrera" can properly be viewed as a lexico-grammatical constructional blend, but this form is also motivated by a blend at the conceptual level. Alcione does not say (as we might suppose a boy might) that she is the cowboy Beto Carrero. Rather, she adopts a name signifying a feminine equivalent of that identity in the fictive world of enactment. Whether this involves a transformation of this fictive world to incorporate other aspects of the Beto Carrero World is unclear from the transcript, since possession of the name "Bete Carrera" is immediately contested, first by Camila, who is now in possession of the hat. Camila says in turn 8 that she too is Bete Carrera. Thaís, who has been in charge of name assignment, first tries in turn 9 to prohibit this appropriation by Camila, then changes her mind and appropriates the name Bete Carrera herself. The transcript ends with the girls all claiming competitively to be called (that is, to be, in the play world of enactment), Bete Carrera.

\subsection{What's in a hat?}

As Smolka, Gões and Pino point out in their article analysing this episode of symbolic play, the cowboy hat, qua artefact, remains a hat, and it is never used by the children as anything other than a hat. At the same time, the cowboy hat "became" —or, rather, came to signify-more than the canonical rules of object-usage that it embodies qua artefact.

Through language, the children created Bete Carrera (Turn 7), the feminine of Beto Carrero ... Language allows for this specific appropriation, for such a construction and transformation; it allows for a 'performance' that synthesizes old and new modes and models of acting. Through language, it is possible to become another, to become homo duplex ... or, in fact, multiplex. In this consists the dramatic character of human experience. (Smolka et al., 1997: 161)

The hat, in this interaction, is simultaneously situated at two levels of meaning and construal. At the first level, its canonical function is appropriated enactively by the participants (by putting it on and taking it off) At this first level, the construal of the hat is intersubjectively shared, non-contested and constant: the hat remains a hat.

At the second level, the hat is invested with a "surplus meaning" which goes beyond its construal as an artefact. At this second level the hat comes also to signify the subjective positionings and perspectives of the individual participants within a more comprehensive, discursively constituted frame. Unlike at the first level of meaning, the construal of the hat changes over time: it is "differently imagined" at different stages of the play. First, it is imagined by Thaís (Turns 1-4) as being an ornamentation, or fashion accessory; then it is "re-imagined" by Alcione (Turn 7) as a particular cowboy hat, indexing a specific and imagined identity (that of the imaginary Bete Carrera). As Smolka et al. point out, both the new meaning of the hat, and the gendered identity which it signifies, are brought into being by means of language and discourse. These meanings are constructed in socially shared cognition: specifically, by the blending of the conceptual space of "Beto Carrero World" into the discourse frame of "playing house". From a collaborative process of conceptual and grammatical blending emerges the new identity signified by "Bete Carrera". 


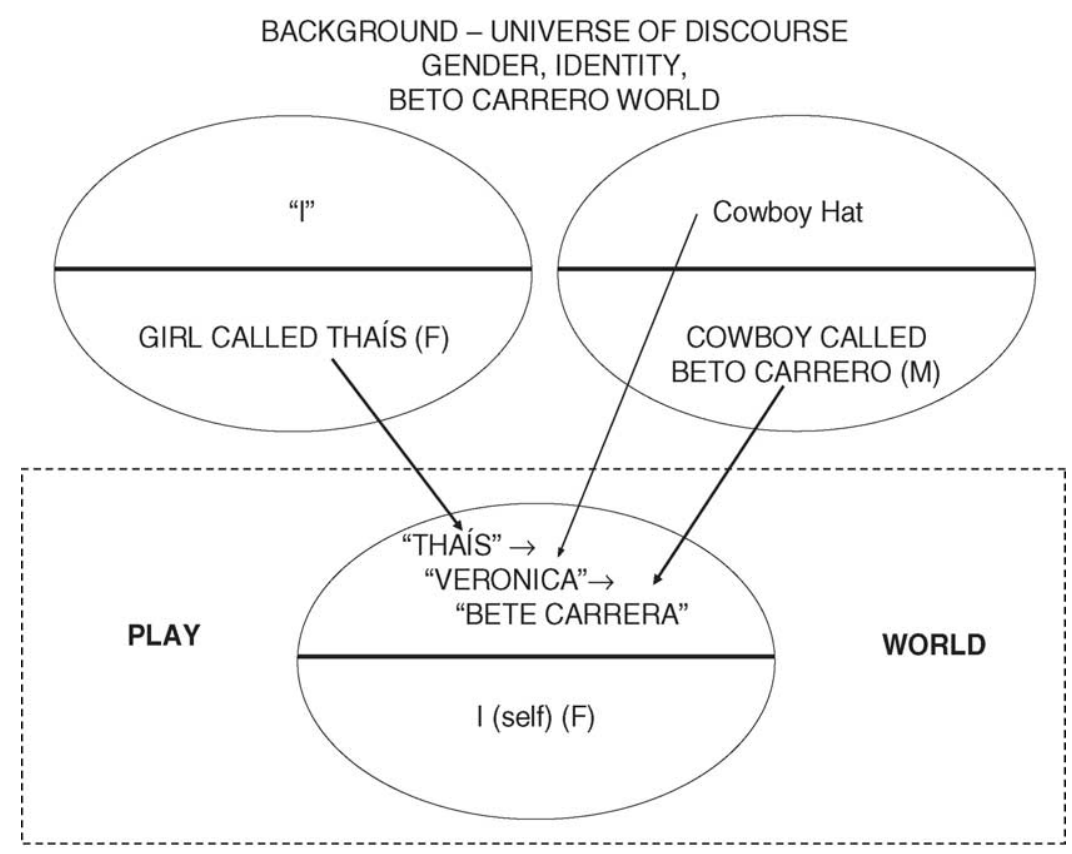

PLAY WORLD as constructed by Thaís

Fig. 2. The construction of Bete Carrera.

\subsection{Blending and signifying}

Fig. 2 is a variant of the standard form of the blending diagram, with two important differences. First, each of the input spaces, as well as the blended space, is horizontally divided in Saussurean fashion into an upper Signifier and lower Signified pair. Second, the diagram makes clear that the two input spaces are focussed or foregrounded within a general background, or shared Universe of Discourse, which includes: (i) the participants (the girls); (ii) the girls' preoccupations with gender and identity; (iii) their shared knowledge of Beto Carrero World; (iv) their metalinguistic awareness of the semantic value of grammatical gender morphology; (v) some familiar conventions of symbolic play. The blended space is the Play World.

Each participant is a self, or "I", with a name (Alcione, Thaís, Camila). This name, in the "non-play" world, is stable, and designates an unalterable identity, but each girl also knows that it is characteristic of the play world that she can adopt another name and identity. Playing with names is one aspect of playing with conventions, and exploring the nature of conventionality and normativity. In Fig. 2, the construction of the play world is diagrammed from the perspective of Thaís, but it is important to note that the entire process depends upon the shared knowledge of the micro-community engaged collaboratively in the symbolic play episode. 
The material setting also includes the cowboy hat, and part of the Universe of Discourse is the shared knowledge that this cowboy hat can be construed, in the conceptual space of Beto Carrero World, as "Beto Carrero's hat", a signifier of the cowboy and "good guy" (desirable, but masculine, identity) Beto Carrero.

In the blended space of the play world, the girls are free to play with their identities. Hence the inversion in Fig. 2 of the Signifier-Signified relationship: the "I" or "self" is now the Signified, which is established in the play discourse, while the names adopted by the girls are Signifiers with meanings which are temporary, and local to the play world. The girls' play identities are unstable, negotiable and shifting, and develop over time. In the transcript, one of the girls has three successive names: she is addressed by her real name (Thaís), then adopts the feminine name "Veronica", and finally shifts to elect for the feminized version of "Beto Carrero", namely "Bete Carrera", which she appropriates from Alcione, who in the play invented this fictive identity. As already stated, Fig. 2 depicts the play world from the perspective of Thaís, although its structure and content (including the fictive identity Bete Carrera) are shared by all three participants.

It is important to note that it is only at the point that the expression "Bete Carrera" is introduced into the discourse (Turn 7, by Alcione), that the right hand input space is blended into the play world as a source of identity construction, rather than as a prop for the playing of mother and daughter roles. One way to analyze this is to say that the right hand input space is not, until the introduction of the expression "Bete Carrera", functioning as a Signifier-Signified couple; rather, up until that point, the hat is simply a hat, contributing to a simpler, first order blend (the blended space which is necessary for all symbolic play). The two arrows from the right hand input space to the names in the blended space attempted to convey this graphically.

The temporal dimension of the blend is an important clue to its collaborative nature. Although the character Bete Carrera is an invention of Alcione, the discourse space for her invention was provided by Thaís, who invited the other girls to choose names, while the previous play by Alcione and Thaís with the cowboy hat can be supposed to have made the domain of Beto Carrero World salient for her. The blend is constructed both step by step, and collaboratively (although, as so often in children's play, the collaboration then gives way to competition for the toys, in this case, the name "Bete Carrera").

\section{Conclusion: blending as microgenesis}

I have presented a re-analysis of a play episode which had previously been analyzed by Smolka et al. (1997), who collected the data, from a Vygotskian perspective focussing on processes of semiotic mediation (both linguistic and artefactual) in the construction of multiplex social roles in children's play. My re-analysis builds on theirs, and is entirely consistent with it. However, enriching the analysis by using the theoretical tools of blending theory permits a closer examination of the interface between cognitive and semiotic processes which constitutes the leading edge of the dynamic, developmental processes unfolding during the episode. I hope thereby to have illustrated and demonstrated the fruitfulness of incorporating blending theory into the developmental perspective. It is 
equally important, however, to stress the importance of the social and the developmental perspectives for blending theory.

Developmental psychology is concerned with changes, and particularly constructive changes yielding complexification and novelty. Valsiner (2000: 17) states that "the developmental perspective in any science entails investigation of general laws of emergence of novelty in irreversible time". The time scales of developmental investigation and developmental (including evolutionary) theory are various, and differ by orders of magnitude. These are usually held to comprise (in descending order of magnitude) phylogenetic, socio-historical, ontogenetic, microgenetic levels (Branco et al., in press). Each level to the left both grounds and includes the levels to its right. Microgenesis is the study of developmental processes unfolding in "real time", often, though not exclusively, in communicative contexts (Karmiloff-Smith, 1992). Valsiner (2000: 78) states that "The crucial feature of the microgenetic orientation ... is the concentration on the unfolding of the INTERMEDIATE FORMS. These intermediate forms can be variable - some are 'preliminary states' of the final forms, others are forms that emerge, but do not develop into a final state. They disappear without arriving in the final form state, yet their importance in the emergence of novelty may be profound." We have seen above, for example, the significance of the intermediate form "Veronica" in the construction of the "Bete Carrera" blend. Because children's interactions and utterances are more likely than those of adults to display, in externalized forms, the intermediate stages of construction of conceptual blends, studies of children's spontaneous interactions provide indispensable insight into the dynamic, microgenetic process of conceptual blending and integration.

In this process, as well as in the ontogenetic development of the individual cognitive capacity for blending, social interaction is central. As Oliveira (1998: 110) points out, in the context of another study of children's interactions and the development of gender concepts and gendered identity, social interactions are best understood as "a dynamic process of expanding or constructing shared semiotically organized fields of conduct." In the course of this process, roles, identities and conventions are continually re-negotiated, against the background of relatively stable socially shared norms and representations. Such norms and representations are not only linguistic: they subsist also in the material setting, through what Hutchins (this issue) calls "the association of conceptual structure with material structure." In this article, I have tried to show, first, that such associations are not necessarily and always stable and culturally entrenched, but may also be negotiated and renegotiated in the course of social interactions; and second, that they are not only cognitive resources for solving computational problems, but also resources for the construction and exploration of self and identity.

\section{References}

Branco, Angela, Pessina, Luciana, Flores, Adriana, Salomão, Sanya, in press. A socio-cultural constructivist approach to metacommunication and child development. In: Branco, A., Valsiner, J., (Eds.), Communication and Metacommunication in Human Development, Ablex, London.

Bruner, Jerome, 1975. From communication to language: a psychological perspective. Cognition 3, $225-287$.

Bruner, Jerome, 1990. Acts of Meaning. Harvard University Press, Cambridge, MA. 
Cole, Michael, Hood, Lois, McDermott, R., 1978. Ecological Niche Picking: Ecological Invalidity as an Axiom of Experimental Psychology. Laboratory of Human Cognition, Rockefeller University.

Fauconnier, Gilles, Turner, Mark, 2002. The Way We Think. Basic Books, New York.

Fodor, Jerry, 2001. The Mind Doesn't Work That Way: the Scope and Limits of Computational Psychology. MIT Press, Cambridge, MA.

Gibson, James, 1979. The Ecological Approach to Visual Perception. Houton Mifflin, Boston.

Hockett, Charles, 1960. Logical considerations in the study of animal communication. In: Lanyon, W.E., Tavolga, W.N. (Eds.), Animal Sounds and Communication. American Institute of Biological Sciences, Washington, DC, pp. 392-430.

Karmiloff-Smith, Annette, 1992. Beyond Modularity. MIT Press, Cambridge, MA

Langacker, Ronald, 1987. Foundations of Cognitive Grammar Vol. 1, Theoretical Prerequisites. Stanford University Press, Stanford.

Lévy-Bruhl, Lucien, 1918. Les Fonctions Mentales dans les Sociétés Inférieures. Alcan, Paris.

Lock, Andrew, 1978. Action, Gesture and Symbol: the Emergence of Language. Academic Press, London.

Longman Dictionary of the English Language (Longman Webster English College Dictionary), 1984. Longman, Harlow.

Oliveira, Zilma de, 1998. Peer interactions and the appropriation of gender representations by young children. In: Lyra, M., Valsiner, J. (Eds.), Construction of Psychological Processes in Interpersonal Communications. Ablex, London, pp. 103-115.

Piaget, Jean, 1977. The Essential Piaget: an Interpretive Reference and Guide. Basic Books, New York.

Rohrer, Tim, 2001. Pragmatism, ideology and embodiment: William James and the Philosophical Foundations of Cognitive Linguistics. In: Dirven, R., Hawkins, B., Sandicioglu, E. (Eds.), Language and Ideology: Cognitive Theoretical Approaches, vol. 1. John Benjamins, Amsterdam, pp. 49-81.

Rubinstein, David, 1981. Marx and Wittgenstein: Social Praxis and Social Explanation. Routledge \& Kegan Paul, London.

Searle, John, 1980. Minds, brains and programs. Behavioral and Brain Sciences 3, 417-424.

Sinha, Chris, 1988. Language and Representation: a Socio-naturalistic Approach to Human Development. Hemel Hempstead, Harvester-Wheatsheaf.

Sinha, Chris, Jensen de López, Kristine, 2000. Language, culture and the embodiment of spatial cognition. Cognitive Linguistics 11, 17-41.

Smolka, Ana-Luisa, de Gões, Maria, Pino, Angel, 1997. (In)determinacy and the semiotic constitution of subjectivity. In: Fogel, A., Lyra, M., Valsiner, J. (Eds.), Dynamics and Indeterminism in Developmental and Social Processes. Earlbaum, Mahwah, NJ, pp. 153-164.

Talmy, Leonard, 1996. Fictive motion in language and perception. In: Bloom, P., Peterson, M., Nadel, L., Garrett, M. (Eds.), Language and Space. MIT Press, Cambridge, MA, pp. 211-276.

Valsiner, Jaan, 1998. The Guided Mind. Harvard University Press, Cambridge, MA.

Valsiner, Jaan, 2000. Culture and Human Development. Sage, London.

Vygotsky, Lev, 1986. Thought and Language. MIT Press, Cambridge, MA.

Wertsch, James, 1985. Vygotsky and the Social Formation of Mind. Harvard University Press, Cambridge, MA.

Wood, David, Bruner, Jerome, Ross, G., 1976. The role of tutoring in problem solving. Journal of Child Psychology and Psychiatry 17, 89-100.

Chris Sinha is Professor of Psychology of Language at the University of Portsmouth. He gained his BA at the University of Sussex and his doctorate at the University of Utrecht. Before moving to Portsmouth, Chris taught in departments of Education, Psychology, and Language and Communication in Britain, the Netherlands, and Denmark. He has published widely in many disciplines, including anthropology, linguistics, education, evolutionary biology, connection science, and developmental and cultural psychology. 